SPECIAL REPORT

\title{
Mobilizing for pedestrian safety: an experiment in community action
}

\author{
A B Bergman, B Gray, J M Moffat, E S Simpson, F P Rivara
}

Injury Prevention 2002;8:264-267

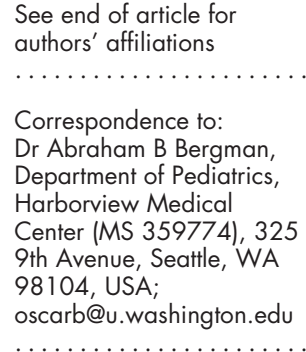

In contrast to the steady reduction in mortality and morbidity from collisions involving motor vehicle occupants, relatively little progress has been made in controlling motor vehicle/pedestrian collisions. Engineering modifications are the most effective means of reducing such collisions, but mainly because of their cost, and public apathy about pedestrian safety, are too rarely employed.

A modest experiment in community action was undertaken by attempting to induce the authorities of 10 small cities to apply for state funds to create a single model pedestrian refuge in their respective communities. Our hope was that this model would later lead to more widespread improvements. The key elements of the campaign were organizing local pedestrian safety task forces, compiling local pedestrian injury statistics, and publicizing the stories of pedestrian injury victims.

At the conclusion of the planning process, all 10 target communities submitted grant applications and all 10 received full grant funding. Five projects were completed as planned, two are under construction, and the plans for three were abandoned.

Pedestrian safety is not an issue that captures public attention. To make progress, goals must be modest, and a dedicated constituency must be developed. "Victim advocacy" is a vital part of this process. Progress in injury control requires concerted community action. v $\mathrm{n}$ most countries a huge gap exists in the field of injury prevention between the knowledge of how to reduce the risks of injuries, and the practical application of that knowledge. Nowhere is this more apparent than in pedestrian safety. Attempts to control injuries from motor vehicle/pedestrian collisions have generally been discouraging. This is in striking contrast to the steady reduction in mortality and morbidity for motor vehicles occupants involved in collisions. Though there has been a $25 \%$ reduction in the number of pedestrians killed in the United States over the past 10 years, from 6556 in 1989 to 4906 in 1999, ${ }^{1}$ this development is thought to be the result of fewer individuals, particularly children, walking rather than because of any intervention measures. ${ }^{2}$ The relative lack of progress is largely due to the multiple factors involved in the origins of motor vehicle/pedestrian collisions, such as the behavior of drivers; the structure of vehicles; the behaviors and the physical and cognitive abilities of pedestrians; and the environmental scenario of the collision sites. Also, the complexity of the problem and the lack of "easy fixes" tends to induce a sense of fatalism that "nothing can be done". Finally, in comparison to motor vehicle occupant injuries, which commonly involve suits against vehicle manufacturers, the economic stakes for pedestrian injuries are low. Hence, there is little financial fuel for prevention efforts.

The common etiologic features of most pedestrian injuries are roadways not designed to accommodate the ever rising number of vehicles that use them, the focus on vehicles rather than pedestrians, and the lack of separate pathways for pedestrians. ${ }^{3-5}$ This scenario is particularly acute in developing countries. ${ }^{6}$

For the past 14 years we at the Harborview Injury Prevention and Research Center (HIPRC) in collaboration with local law enforcement agencies, the Washington State Traffic Safety Commission, the Washington State Department of Transportation (WSDOT), and the King County Department of Engineering have devoted considerable effort to enhancing pedestrian safety. This effort consisted of securing passage and strict enforcement of state laws protecting pedestrians at intersections and in marked crosswalks, and teaching pedestrian skills to young schoolchildren. Unfortunately, the effects, if present at all, were modest. For example, after passage of stricter state laws and increased enforcement in Seattle neighborhoods, we sought to determine whether cars were more apt to stop for pedestrians. No change in driver behavior was discernible. ${ }^{7}$ Likewise, evaluation of the pedestrian skills of children in kindergarten through grade 3 taking the Wary Walker course showed small benefits in approximately half of those participating. However, even after the intervention, half the children still had unsafe pedestrian behavior. ${ }^{8}$ Clearly other approaches were needed.

\section{ENVIRONMENTAL MODIFICATION}

At the beginning of our efforts in pedestrian safety, we were well aware that engineering modifications had the potential for a much greater impact than education and enforcement. ${ }^{90}$ Clearly, pedestrians, as well as cyclists, are safest when they are separated from motor vehicles. Conversely it also has been shown that pedestrian injury rates are highest in areas without sidewalks along with fast moving traffic. ${ }^{11}$ The main impediment for engineering modifications to promote pedestrian safety, however, is cost. Changing laws, increasing enforcement efforts, and teaching children about pedestrian safety are all cheaper than installing signals, building curb extensions to reduce crossing distances, and constructing sidewalks. The cost of a traffic signal, for example, the device most sought after by citizens desiring pedestrian safety enhancements, ranges between $\$ 60000-$ $\$ 250000$ depending on the complexity of the system.

\section{PEDESTRIAN REFUGES}

A series of reports on the effectiveness of crossing refuge islands as relatively inexpensive devices to protect pedestrians caused us to change the focus of our intervention efforts.

Abbreviations: HIPRC, Harborview Injury Prevention and Research Center; WSDOT, Washington State Department of Transportation 


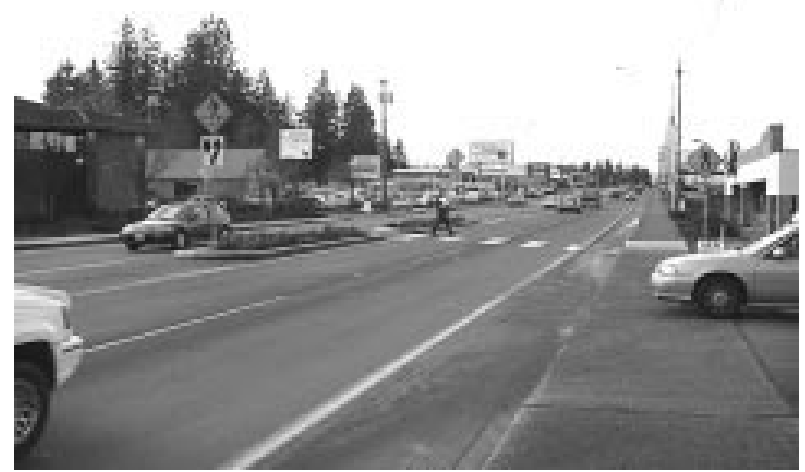

Figure 1 Photograph of a pedestrian refuge island in a busy four lane arterial highway.

Pedestrian refuges or crossing islands are raised islands in the center of roadways (see fig 1 ), allowing pedestrians to cross one half of the street, with a safe place to stop before crossing to the other side of the street. They are typically constructed at marked crosswalks, either at a mid-block location or at an intersection. The crossing islands are best employed when: (a) traffic volumes result in few gaps for pedestrians to safely cross the entire street, (b) there is little demand to make left turns at the site, and (c) the crossing island can be accommodated within an existing left turn pocket or center two way left turn, and (d) the roadway is particularly wide, such as one with four lanes. Depending on the complexity of construction, refuge islands usually cost between $\$ 2000$ and \$20 000 .

In 1993 Brilon and Blanke published a series of studies on the effect of traffic calming measures in six German cities. They concluded that, "the modification of streets has proven to be more effective than the introduction of a speed limit of $30 \mathrm{~km} / \mathrm{h}$. The weaker road users, children, pedestrians, and cyclists have benefited most from the measures" ${ }^{12}$ In a report for the Road Safety Division of the British Department of Transportation evaluating 200 traffic calming schemes in the UK, Webster and Mackie state that "comparisons of 'before' and 'after' crash data show the average annual motor vehicle/ pedestrian collisions frequency fell by about $60 \%{ }^{\prime \prime} .^{13}$

\section{CONVINCING PLANNERS AND POLITICIANS}

It is not those working in injury prevention research who need convincing about the value of pedestrian refuges. Rather it is the planners and engineers who design roadways, and the politicians who appropriate the funds who determine whether abstract concepts become real. Specifically, we sought to influence the leaders of small cities in South King County to construct model crossing islands. We hoped that positive responses to the model safety measures in the participating cities would lead to the installation of a larger number of crossing islands, along with other pedestrian safety measures throughout the region.

Who would pay for the safety improvements? The resources of small cities are limited. However since our targets were state roadways, we looked to state highway construction funds. Since 1994, the Washington State Transportation Improvement Board has distributed over 12 million dollars to pedestrian safety and mobility projects through their Pedestrian Facilities Program. This program, open to all local governments in Washington State, draws from federal funds and requires a $20 \%$ match by the town or city that receives the grant.

We did not select a diminution in the number of pedestrian injuries as our outcome measure; they are relatively rare events. Rather we viewed ourselves as carrying out an experiment in community action. Our admittedly modest goal was to determine how many cities would participate in the planning process, and how many would install model pedestrian safety crossing islands.

\section{ELEMENTS OF CAMPAIGN}

The key elements of the campaign were broadening the constituency for pedestrian safety, compiling local pedestrian injury statistics, and publicizing the stories of injury victims.

\section{Broadening the constituency}

Traditionally, pedestrian injuries occupy the attention of only traffic safety officials and highway engineers. We attempted to broaden the appeal by stressing both the health and environmental implications of pedestrian trauma. One of our themes was: "Citizens, especially senior citizens and children who constitute the largest groups of pedestrian trauma victims, should have the right to stroll peacefully and safely in their communities".

\section{Statistics}

For action to be taken, local officials had to be convinced that pedestrian injuries were an important problem in their local community, and that a feasible means of prevention was available. Accordingly we publicized pedestrian injury statistics to show that South King County had one of the highest rates in Washington State.

\section{Victim stories}

It was deemed imperative to create a personal, emotional link with the public to the victims of traffic crashes. As illustrated by the content of local television news broadcasts, the stories of individual victims of tragedies carry more power than reams of statistics. The impetus for our own efforts in South King County came, not from the trauma statistics, but from the serious injuries sustained by the child of a physician who lived and practiced in South King County.

\section{GETTING OUT THE WORD}

How was our message conveyed to public officials? Lacking funds for advertising, we depended on local media who hover over our regional trauma center for news of the latest tragedies. That our prevention campaigns emanate from this center, and provide the media with access to some trauma victims, gives us a large public relations advantage. The most important outlet was the South County Journal, a small daily serving the communities in our target area. One of us (ESS) spoke regularly at luncheon meetings of service organizations in the area.

Media respond to late-breaking news, not chronic problems. Therefore, ghoulish as it may sound, we waited for a tragedy to occur before kicking off our campaign. On 21 February 1997 a 2 year old child was killed as she, her mother, brother, and sister were attempting to cross a five lane road in the city of Auburn during peak hour traffic on a Friday afternoon (see fig 2). In trying to cross the street to catch a bus, the family paused in the two way left turn lane, and were struck by a truck emerging from a driveway into the left turn lane.

The following week we organized a press conference in the Auburn City Hall. King County Executive Ron Sims announced that he was asking physicians at Harborview Medical Center (the hospital is owned by the county) to report back to him in three months on ways in which the risks to pedestrians in South King County could be reduced (see fig 3).

The mayors, police chiefs, and traffic engineers of several of the surrounding cities were in attendance. One of us (JMM) showed photographs of the site where the child was struck, and demonstrated the extreme difficulty encountered by pedestrians attempting to cross that roadway. The speaker who drew the most media attention, however, was the local physician, who with her son at her side, made an emotional plea for action to make the roadways safer for pedestrians. 


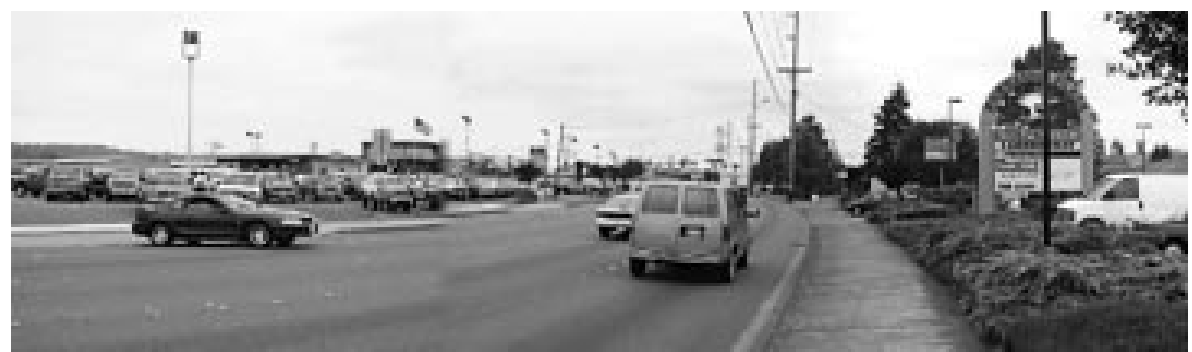

Figure 2 Scene of accident on Auburn Way where child was killed by car using the two way left turn lane, 21 February 1997.
Executive Sims "requested" the County Health Department to allocate \$25000 for one year to match an equal sum from the Washington State Traffic Safety Commission. At the press conference we learned that Sims had been struck by a car when he was 6 years old. The money was used to hire an urban planner (BG) to coordinate the campaign.

With a coordinator in place, the South King County Improvements for Pedestrians Project got underway. The program was billed as "a partnership among local communities, city staff, health and safety professionals and elected officials to make south King County roadways safer for pedestrians". Executive Sims appointed a work group to oversee the program. The group included representatives from the HIPRC, the Departments of Public Health, Public Works and Transportation of King County, the Puget Sound Pedestrian Coalition, the WSDOT, and Traffic Safety Commission. The next step was a larger community meeting to keep the project in front of the media, and capture the attention of local politicians.

\section{PEDESTRIAN SAFETY SUMMIT}

Over 60 elected officials, planners, engineers, and others who make decisions about street design, attended the June 1997

South County Journal

Friday, February 28, 1997

\section{Tot's death leads}

\section{Sims to \\ establish safety task}

\section{force}

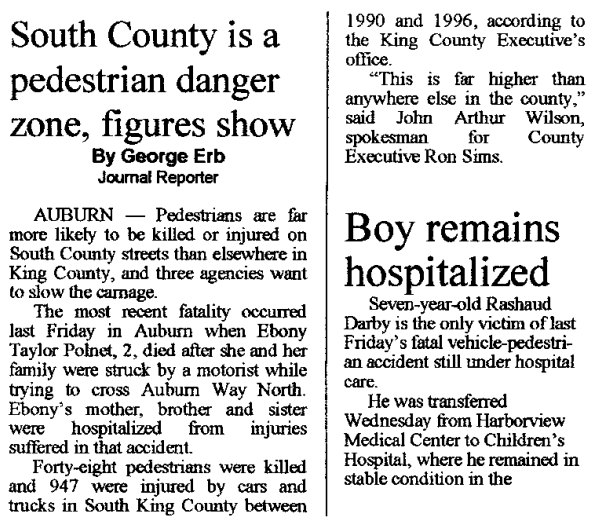

Figure 3 Story about formation of pedestrian safety task force in edition of South County Journal, 28 February 1997.
Pedestrian Safety Summit. Conspicuously present were several state legislators, who would have to exert their influence to obtain the state transportation funds to benefit their constituent communities. It was not necessary to convert this audience to the importance of pedestrian safety. It was necessary to demonstrate to them an economical intervention that would work. For that purpose we imported as keynote speaker, Dan Burden, Executive Director of Walkable Communities, one of the country's most knowledgeable and charismatic figures in pedestrian safety. A captivating feature of Burden's presentation, was how traffic calming and pedestrian safety enhancement can revitalize neighborhood business districts, a message that was well received by local politicians. ${ }^{14}$

\section{IDENTIFYING DEMONSTRATION SITES}

The summit was an effective kick-off event; next came the work of selecting project sites. Before the summit, the work group assembled a list of sites throughout the county that would be suitable for the program. Each demonstration site needed to be a one mile section of roadway with a history of pedestrian accidents. The initial list was based on statistics (WSDOT's pedestrian accident locations) and was modified at the summit based on comments from community members and local engineering department staff. Based on the grant criteria, the work group was able to narrow the list of demonstration sites to the 10 they felt were most competitive for Transportation Improvement Board funding.

\section{LOCAL TASK FORCES}

A local task force was appointed for each of the jurisdictions participating in the program. The membership represented local business owners; city staff from police, fire, and safety departments; a school district pupil transportation coordinator; state or county transportation agency staff; a community health coordinator; an elected official; King County/Metro Transit staff; and the project coordinator.

Each task force participated in a design workshop to determine the projects to be included in the Transportation Improvement Board application. The design workshops include a slide show to meet the program goal of raising awareness about pedestrian safety threats and possible solutions. Maps and photographs of the demonstration site were all reviewed by each task force, along with accident history. Major destinations for pedestrians were identified to help the group determine frequently used walking routes.

A range of solutions were identified based on the physical constraints of the site, cost, construction feasibility, related projects, and community or political support for the improvements. The group developed preliminary designs and discussed funding needs, potential sources of funding, and project timelines. At the conclusion of the planning process in January 1998 all 10 target communities submitted grant applications to the Transportation Improvement Board and all 10 received full grant funding. Key elements in promoting pedestrian safety are listed in box 1. The timeline for the South King County Improvements for Pedestrians Project is shown in box 2.

At the time of this writing (June 2002), five of the projects were completed as planned; two in Auburn, two in Federal 
Box 1: Key elements in promoting pedestrian safety goals

- Recognize pedestrian safety as health and livability issues instead of one that is just related to traffic.

- Organize a broad based coalition to advocate for pedestrian safety. Representation should come from the fields of health, safety, traffic engineering, environmental enhancement, along with trauma victims and their families.

- Involve decision makers early in planning process, and keep them apprised with regular updates.

- Forge an emotional connection with the general public and their elected representatives through the testimony of pedestrian injury victims and their families.

Box 2: Timeline of South King County Improvements for Pedestrians Project

1. Forging basic coalition of the HIPRC, Washington State Traffic Safety Commission, and King County Department of Transportation (1989 to present).

2. Agreement by coalition to focus on pedestrian refuges as a goal (January 1995)

3. Agreement by coalition to focus on small cities in South King County after the injury to physician's son (September 1995).

4. Campaign kick-off at press conference after death of child in Auburn (February 1997).

5. Formation of South King County Improvement for Pedestrians Project and hiring of coordinator (May 1997)

6. Convening of Pedestrian Safety Summit (June 1997)

7. Formation and deliberations of local pedestrian safety work groups (July to September 1997).

8. Submission of proposals to Transportation Improvement Board (January 1998).

9. Award of grants for 10 sites (May 1998).

Way, and one in White Center. Three of the projects were withdrawn because of, as stated to the Transportation Improvement Board, "bad cost estimates". Two of those were in Kent and one in Auburn. Another two, in Kent and Des Moines, were incorporated into larger traffic safety projects, and are under construction.

\section{CONCLUSIONS}

When the HIPRC was launched in 1983, we sought guidance from the father of modern injury prevention, Professor Ragnar Berfenstam of Uppsala. Among other things he stressed the importance of linking research and intervention, organizing coalitions around specific injury issues, and continually educating the public through mass media about the incidence and consequences of trauma. These principles were followed in this campaign.

Our goals were modest: inducing city authorities to apply for state funds to create a model pedestrian refuge in their communities. Even so, the process was not easy. Ten demonstration sites were funded; seven of them were built or are under construction. There is no guarantee, however, that the presence of the model refuges will lead to communitywide application of these safety enhancements. As stated earlier, the main impediment is the low priority of pedestrian safety on the public's agenda. Our experience provides several lessons on how this might be addressed.

First, progress in pedestrian safety occurs in small steps. Limited and realistic goals must be set. The work group was able to meet all the goals established at the outset of the project. Getting all 10 projects funded exceeded our expectations.

Second, the importance of bringing decision makers into the process early and providing them with regular updates was reinforced. The city of Kent elected not to construct two of the pedestrian refuges even after a grant was awarded. We think this was because the staff member who participated in the planning process left his position, and his replacement was less interested. Third, media coverage was critical to raising the awareness of public officials. The initial press conference and Pedestrian Safety Summit kept the local newspaper engaged enough to write a series of articles throughout the process.

Most important, the power of victim stories was again demonstrated. An emotional link must be created between the public and the families of trauma victims. Centering our kick-off on the events surrounding the death of a child gave the campaign vital energy. Employing "victim advocacy" is imperative if trauma prevention programs are to succeed. This technique has been best practiced and described by personnel of the Trauma Foundation in San Francisco. ${ }^{15}$

Our mistakes are also instructive. We should have helped the local task forces continue as ongoing bodies instead of allowing them to disband at the end of the planning process. The knowledge and energy mobilized by these individuals were needed to continue working with the local engineering staff as the pedestrian safety measures were designed for construction. It was at this point that some of the jurisdictions began to "lose interest" in building the projects they had agreed to though the South King County Improvement for Pedestrians Project process. It is imperative that there be a committed and ongoing constituency for any injury problem, if mortality, morbidity, and disability from trauma are to be reduced.

\section{ACKNOWLEDGEMENT}

We are grateful to Suzanne J Fiala, MD, and Adrian Fiala-Clark for their vital contributions to the South King County Improvement for Pedestrians Project.

\section{Authors' affiliations}

A B Bergman, B Gray, J M Moffat, E S Simpson, F P Rivara, Harborview Injury Prevention and Research Center of the University of Washington and the Washington State Traffic Safety Commission

\section{REFERENCES}

1 National Highway Transportation Safety Administration. Traffic safety facts. Washington, DC: US Department of Transportation (publication HS 809094 US), 1999: 1.

2 Roberts I. Why have child pedestrian death rates fallen? BM 1993;306: 1737-9.

3 Stevenson M. Childhood pedestrian injuries; what can changes to the road environment achieve. Aust N Z J Public Health 1997;21:33-7.

4 Macpherson A, Roberts I, Pless IB. Children's exposure to traffic and pedestrian injuries. Am J Public Health 1998:88:1840-3.

5 Kraus JF, Hooten EG, Brown KA, et al. Child pedestrian and bicyclist injuries: results of community surveillance and a case-control study. Inj Prev 1996;2:212-8

6 Mock CN, Foriuoh SN, Rivara FP. Epidemiology of transport-related injuries in Ghana. Accid Anal Prev 1999:31:359-70.

7 Britt JW, Bergman AB, Moffat J. Law enforcement, pedestrian safety, and crosswalk laws: Evaluation of a four-year Seattle campaign. Transportation research record No 1485. Washington, DC: Transportation Research Board, National Academy Press, 1995: 160-7.

8 Rivara FP, Booth CL, Bergman AB, et al. Prevention of pedestrian injuries to children: effectiveness of a school training program. Pediatrics 1991;88:770-5.

9 Haddon W Jr. Energy damage and the 10 countermeasure strategies. 1973. Inj Prev 1999 5:331-5.

10 Roberts I, Ashton T, Dunn R, et al. Preventing child pedestrian injury: pedestrian education or traffic calming? Aust J Public Health 1994; 18:209-12.

11 Roberts I, Norton R, Jackson R, et al. Effect of environmental factors on risk of injury of child pedestrians. BMU 1995:310:91-4

12 Brilon W, Blanke, H. Extensive traffic calming: results of the accident analysis in 6 model towns. UTE 1993 compendium of technical papers. Washington DC: Institute of Transportation Engineers, 1993: 119-23.

13 Webster DC, Mackie AM. Review of traffic calming schemes in 20 mph zones. Berkshire, UK: Transport Research Laboratory Report 215, 1996 : 41 .

14 Burden D. Street design guidelines for healthy neighborhoods. Sacramento, CA: Land Use Publications, Local Government Commission, 1999: 43.

15 http://www.tf.org/tf 